Www.jmscr.igmpublication.org

Index Copernicus Value: 79.54

ISSN (e)-2347-176x ISSN (p) 2455-0450

crossrefDOI: https://dx.doi.org/10.18535/jmscr/v7i3.195

Original Research Article

\title{
A Prospective Study of Prescription Patterns of Antihypertensive Drugs in Hypertensive Patients at a Tertiary Care Hospital
}

\author{
Authors \\ Rajesh Kumar Jangir ${ }^{1}$, Akhtar Ali ${ }^{*}$, Javed Ahamed ${ }^{1}$, Anusuya Gehlot ${ }^{2}$, Archna Vyas ${ }^{1}$, \\ Kamal Kumar Batar ${ }^{1}$ \\ ${ }^{1}$ Resident, Department of Pharmacology, Dr. S.N. Medical College Jodhpur (Rajasthan) \\ ${ }^{2}$ Head of the department and Senior Professor, Department of Pharmacology, Dr. S.N. Medical College \\ Jodhpur (Rajasthan) \\ *Corresponding Author \\ Dr Akhtar Ali \\ Resident, Department of Pharmacology, Dr. S.N. Medical College Jodhpur (Rajasthan), India \\ Email:drakhtar06@gmail.com, Mobile No-8058961071
}

\begin{abstract}
Aims: To evaluate the prescribing pattern among hypertensive patients and analysis these prescriptions to help in improving the quality of care provided.

Methodology: This was a prospective and observational study. Patients of both sex and all age groups those attended the outpatient department (OPD) were included in this study. Acute cerebrovascular accident, acute MI, acute left ventricular failure and pregnant women were excluded from this study.

Results: Out of 350 patients, 193 (55.14\%) were male and 157 (44.85\%) were female. The average number of drugs prescribed per prescription was 2.52 in our study with a range of 1 to 7 . A maximum number of patients $(40.86 \%)$ were received two antihypertensive drugs followed by single antihypertensive drug (34.85\%). CCB was the most common (39.14\%) used antihypertensive drugs. Total 138 (39.42\%) patients were prescribed fixed-dose drug combination, among this Atenolol + amlodipine FDC was the most commonly used FDC( $40.28 \%)$

Conclusion: Hypertension and its complications can be controlled by diet control, regular exercise, medicines and by time to time follow up. Most commonly prescribed drugs were CCB in this study and ACE inhibitors was most commonly prescribed in diabetic patients. While most common prescribed antihypertensive drug in IHD patients was beta blockers.

Keywords: Prescription Pattern, Antihypertensive drugs, Calcium Channel Blocker, FDC.
\end{abstract}

\section{Introduction}

Hypertension is a major health problem throughout the world and it continues to be an important public health concern because is associated with morbidity, mortality and economic impact on the society. It is a significant risk factor for cardiovascular, cerebrovascular and renal complications ${ }^{1}$. In terms of attributable deaths, raised blood pressure is one of the leading behavioral and physiological risk factor to which $13 \%$ of global deaths are attributed. Hypertension is reported to be the fourth contributor to 
premature death in developed countries and the seventh in developing countries ${ }^{2}$. A whopping 9.4 million death occurs worldwide every year because of cardiovascular diseases and in India, these are estimated to be responsible for 1.5 million deaths annually ${ }^{3}$. According to Directorate General of Health Services, Ministry of Health and Family Welfare, Government of India, the overall prevalence of hypertension in India by 2020 will be $159.46 / 1000$ population ${ }^{4}$.

Hypertension is a very common disorder, particularly past middle age. It is not a disease itself, but it is an important risk factor for cardiovascular mortality and morbidity. The continuous relationship between the level of blood pressure and cardiovascular risk makes any numerical definition and classification of hypertension somewhat arbitrary. Therefore, a definition of hypertension is usually taken as that level of arterial blood pressure associated with doubling of long team cardiovascular risk ${ }^{5}$.

The basis of the measurement of blood pressure established by the description of the stethoscopic sounds by Nikolai Sergeyevich Korotkoff in 1905 enabled research to grow from anecdotal to objective approaches. ${ }^{6}$

Antihypertensive drugs are prescribed mainly to reduce the morbidity and mortality caused by hypertension and its complications. Many a time patient require more than one drugs for effective control of hypertension. Various classes of antihypertensive drugs like diuretics, inhibitor of renin-angiotensin system, Calcium Channel Blockers (CCBs) and Beta Blockers (BBs) have been shown to reduce complications of hypertension and may be used for initial drug therapy ${ }^{7}$.

Several guidelines on its classification and management have been developed. Some of the bodies which have developed guidelines are American Society of Hypertension/International Society of Hypertension (ASH/ISH), Joint National Committee (JNC) on Detection, Evaluation and Treatment of high blood pressure, European Society of Hypertension (ESH)
/European Society of Cardiology (ESC), National Institute for Health and Care Excellence (NICE) and Japanese Society of Hypertension. The JNC VIII guidelines published in 2014 are the most recent guidelines for the management of hypertension in different clinical settings. These guidelines were developed based on a systematic review of the literature to help clinicians. The available guideline recommends different goal BP level and drug treatment options according to the patient's individual clinical need ${ }^{8}$.

The development of drug prescribing pattern was sparked by initiatives taken in Northern Europe and the United Kingdom in the mid-1960s. ${ }^{9}$ The ultimate goal of drug prescribing pattern must be to assess whether drug therapy is rational or not. To reach this goal, methods for auditing drug therapy towards rationality are necessary ${ }^{10}$.

\section{Material and Methods}

This was a prospective and observational study. The diagnosis and line of treatment to be given was decided by the physician in charge of the Department of Medicine. No additional drugs or investigations were advised by us during the study period. Patients of both sex and all adults age groups will be attending the outpatient department (OPD) and would be prescribed antihypertensive drugs were selected for the study. Patients with a hypertensive emergency, cerebral stroke, acute myocardial infarction, Acute left ventricular failure and pregnant women excluded from this study. All the information related to the patients such as name, age, sex, occupation, personal history including smoking status, relevant medical history, past history, family history, and investigations details were obtained from the patient's case file and were recorded in the Case Record Form.

All the pharmacotherapeutic agents used during the treatment of Hypertension were recorded in details. The dose of the drug, duration of treatment, the frequency of administration and dosage form, were recorded in Case Record Form. 
After recording the obtained information in the Case Record Form the data were analyzed further as a demographic profile of study patients and Drug prescribing pattern including routes of administration, type of therapy (Monotherapy / Combination therapy), the category of the drug used in the treatment and fixed-dose combination prescribed.

\section{Results}

\section{Age \& Sex Distribution of Study Patients}

Out of350 patients, 193 (55.14\%) were male and $157(44.85 \%)$ were female. Maximum patients belonged to the age group of more than 59 years$210(60 \%)$, followed by age group 50-59 years$97(27.71 \%)$ and age group $40-49$ years-33 (9.42\%). In this study, no patient of either sex was diagnosed in the age group 18-29 years while in the age group $30-39$ years-10 (2.85\%) only male patients were detected with hypertension. The mean age of male patients was $61.66+11.79$ years and female was found $61.83+9.89$ years. Mean age of total patients was $61.74+10.96$ years (Table 1, Figure 1).

Table 1: Age and Sex Distribution of Study Patients

\begin{tabular}{|l|c|c|c|c|c|}
\hline \multirow{2}{*}{ Age $(\mathrm{yrs})$} & \multicolumn{2}{|c|}{ Male } & \multicolumn{2}{c|}{ Female } & \multirow{2}{*}{ Total } \\
\cline { 2 - 5 } & $\mathrm{N}$ & $\%$ & $\mathrm{~N}$ & $\%$ & \\
\hline $18-29$ & 0 & 0.00 & 0 & 0.00 & 0 \\
\hline $30-39$ & 10 & 5.18 & 0 & 0.00 & 10 \\
\hline $40-49$ & 21 & 10.88 & 12 & 7.64 & 33 \\
\hline $50-59$ & 43 & 22.28 & 54 & 34.39 & 97 \\
\hline$>59$ & 119 & 61.66 & 91 & 57.96 & 210 \\
\hline Total & 193 & 100.00 & 157 & 100 & 350 \\
\hline Mean+SD & $61.66+11.79$ & \multicolumn{2}{|c|}{$61.83+9.89$} & $61.74+10.96$ \\
\hline
\end{tabular}

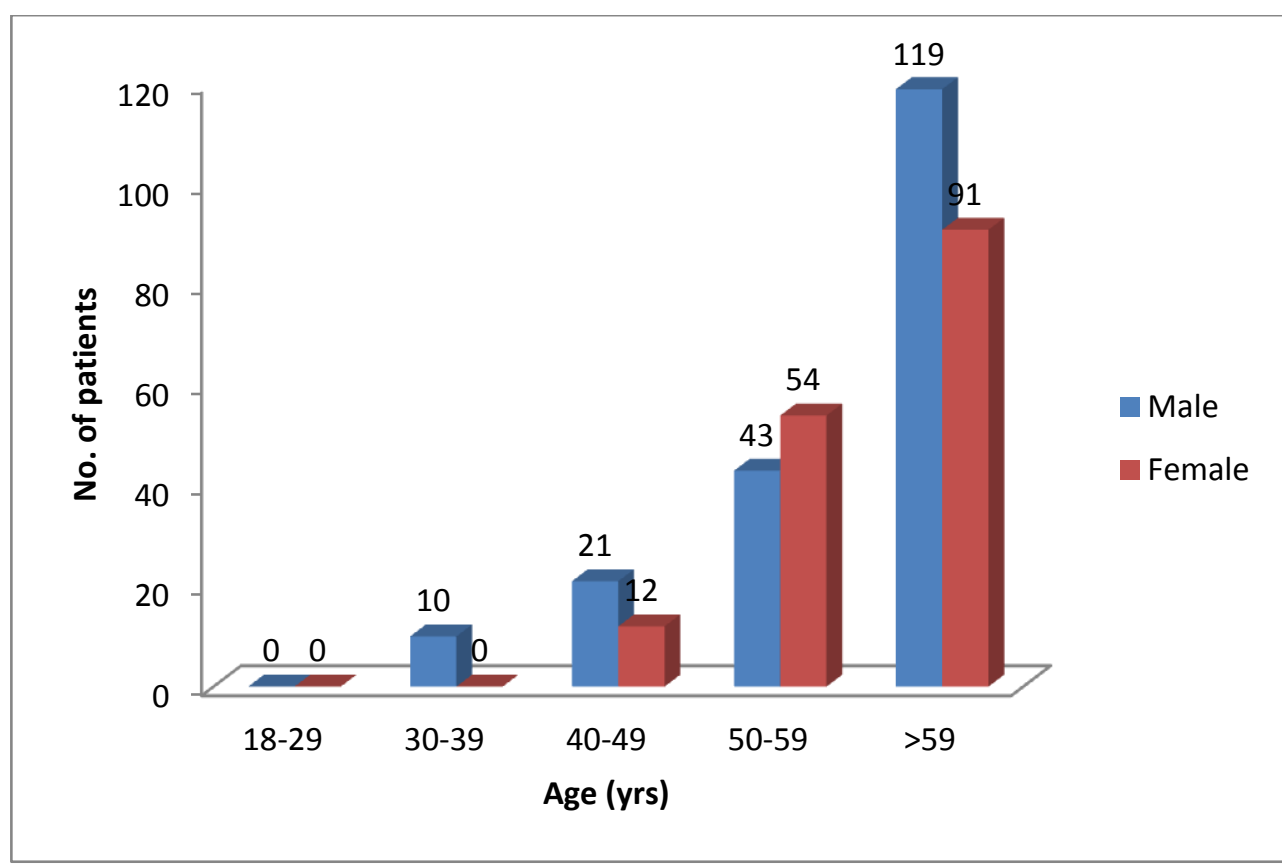

Figure 1: Age and Sex Distribution of Study Patients. Maximum patients belonged to the age group of more than 59 years and there are no patients less than 30 years of age.

Number of Total Drugs Prescribed Per Prescription

A maximum number of drugs prescribed in this study was seven which were prescribed to 2 patients of hypertension with co-morbid condition IHD. A maximum number of drugs prescribed in categories- hypertension alone, total 457 drugs prescribed in patients of hypertension alone and 
no. of patients in this category was 235 , so mean no. of drugs prescribed in this category was 1.94 . Total 315 drugs prescribed in patients with comorbid condition diabetes mellitus and no. of patients in this category was 95 , so mean drugs prescribed in this category was 3.31. In patients with the co-morbid condition, IHD totals 93 drugs prescribed in 17 patients so mean no. of drugs prescribed in this category was 5.47.In patients with CHF total of 17 drugs prescribed in 3 patients so mean no.of drugs prescribed in this category was 5.6. None of the patients with comorbid condition received less than two drugs. The average number of drugs prescribed per prescription was 2.52 in our study with a range of 1 to 7 . (Table2, Figure 2).

Table 2: Number of total drugs prescribed per Prescription

\begin{tabular}{|c|c|c|c|c|c|}
\hline $\begin{array}{l}\text { No. } \\
\text { drugs }\end{array}$ & $\begin{array}{l}\text { No. of patients } \\
\text { hypertension } \\
\text { alone }(\mathrm{N}=235)\end{array}$ & $\begin{array}{l}\text { No. of patients } \\
\text { hypertensions co- } \\
\text { morbid DM } \\
(\mathrm{N}=95)\end{array}$ & $\begin{array}{l}\text { No. of patients } \\
\text { hypertension co- } \\
\text { morbid with } \\
\text { IHD }(\mathrm{N}=17)\end{array}$ & $\begin{array}{l}\text { No. of patients } \\
\text { hypertension co- } \\
\text { morbid with } \\
\text { CHF }(\mathrm{N}=3)\end{array}$ & $\begin{array}{c}\text { Total no } \\
\text { of } \\
\text { patients } \\
n=350\end{array}$ \\
\hline 1 & 81 & 0 & 0 & 0 & 81 \\
\hline 2 & 96 & 20 & 0 & 0 & 116 \\
\hline 3 & 48 & 38 & 0 & 0 & 86 \\
\hline 4 & 10 & 25 & 2 & 0 & 37 \\
\hline 5 & 0 & 11 & 7 & 1 & 19 \\
\hline 6 & 0 & 1 & 6 & 2 & 9 \\
\hline 7 & 0 & 0 & 2 & 0 & 2 \\
\hline Total & 457 & 315 & 93 & 17 & 882 \\
\hline $\begin{array}{l}\text { Average no. } \\
\text { of drugs }\end{array}$ & 1.94 & 3.31 & 5.47 & 5.6 & 2.52 \\
\hline
\end{tabular}

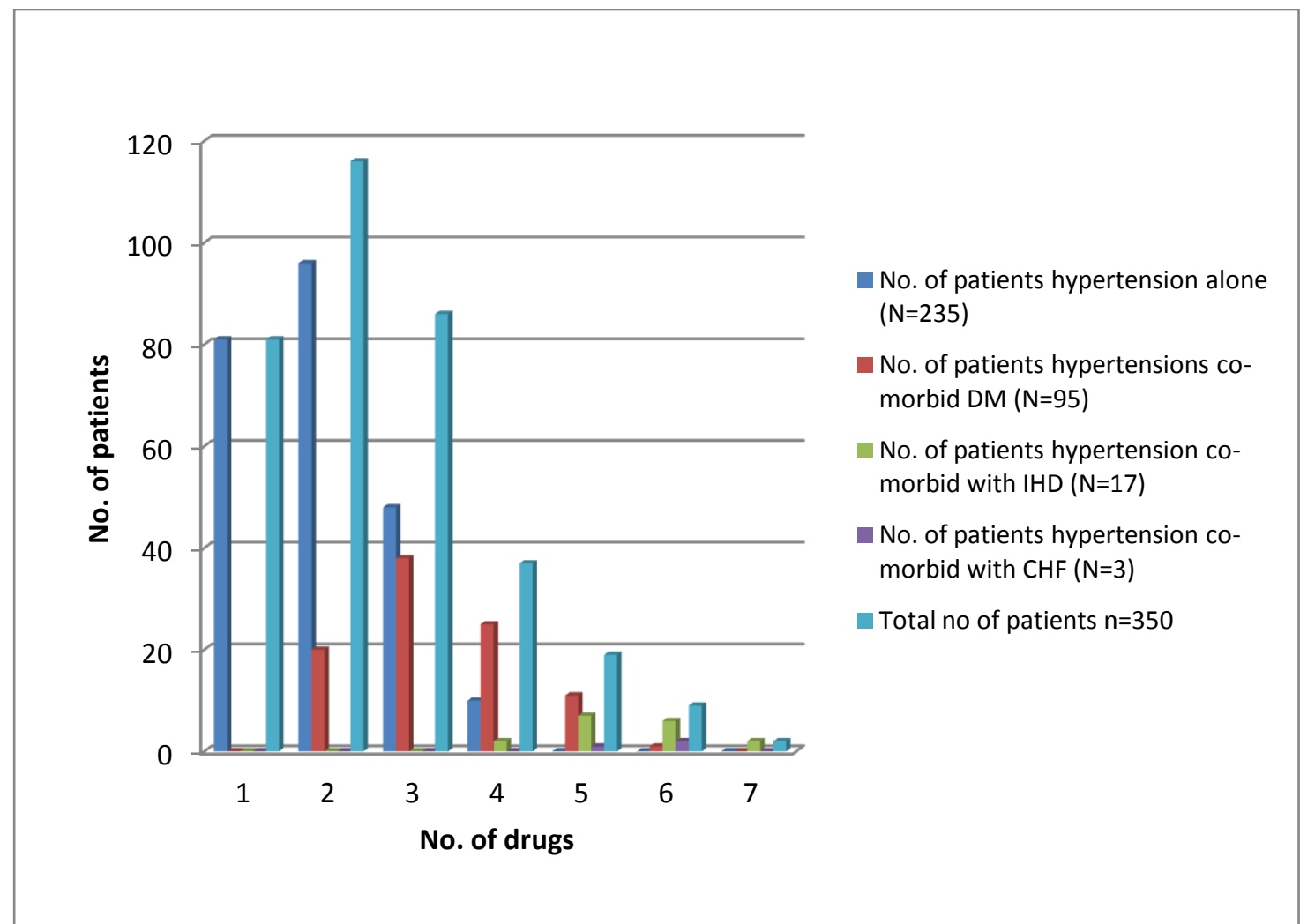

Figure 2: Number of Total Drugs Prescribed Per Prescription. A maximum number of drugs prescribed in categories- hypertension alone. The average number of drugs prescribed per prescription was 2.52 in our study with a range of 1 to 7 . 
Antihypertensive drugs prescribed per prescription

In this study, we found patients received antihypertensive drugs ranging from 1 to 4 . A maximum number of patients $(40.86 \%)$ were on two drugs followed by single drug $(34.85 \%)$ and three drugs $(20.57 \%)$. Only $3.71 \%$ of patients received four drugs. In the group of patients of hypertension alone, a mean number of antihypertensive drugs was found $1.94-34.46 \%$ received one antihypertensive drug. $40.85 \%$ of patients have prescribed two drugs. $20.42 \%$ and $7.23 \%$ of patients in this category received three and four drugs respectively. In the group of patients of hypertension with diabetes, ischemic heart disease and CHF mean a number of antihypertensives were 1.77, 2.52, and 2.66 respectively. In the group of hypertension comorbid with diabetes $41.05 \%$ of patients were on monotherapy while $42.10 \%$ and $15.79 \%$ of patients received two and three drugs in this category. In the group of hypertension comorbid with ischemic heart disease, the highest numbers of patients $(41.17 \%)$ were prescribed three drugs while $35.29 \%$ of patients were prescribed two drugs. An equal proportion of patients $(11.76 \%)$ were prescribed the single drug and four drugs. 2 out of 3 patients of hypertension comorbid with CHF received three antihypertensive drugs while one received two drugs. (Table 3, Figure 3.)

Table 3: No. of antihypertensive drugs prescribed per prescription

\begin{tabular}{|l|c|c|c|c|c|}
\hline $\begin{array}{l}\text { No. } \\
\text { drugs }\end{array}$ & $\begin{array}{c}\text { No. of patients } \\
\text { of hypertension } \\
\text { alone (N=235) }\end{array}$ & $\begin{array}{c}\text { No. of patients } \\
\text { of hypertension } \\
\text { co-morbid with } \\
\text { DM (N=95) }\end{array}$ & $\begin{array}{c}\text { No. of patients of } \\
\text { hypertension co- } \\
\text { morbid with IHD } \\
(\mathrm{N}=17)\end{array}$ & $\begin{array}{c}\text { No. of patients } \\
\text { of hypertension } \\
\text { co-morbid with } \\
\text { CHF (N=3) }\end{array}$ & $\begin{array}{c}\text { Total no. of } \\
\text { patients } \\
\text { N=350 }\end{array}$ \\
\hline 1 & $81(34.46 \%)$ & $39(41.05 \%)$ & $2(11.76 \%)$ & 0 & $122(34.85 \%)$ \\
\hline 2 & $96(40.85 \%)$ & $40(42.10 \%)$ & $6(35.29 \%)$ & $1(33.33 \%)$ & $143(40.86 \%)$ \\
\hline 3 & $48(20.42 \%)$ & $15(15.79 \%)$ & $7(41.17 \%)$ & $2(66.66 \%)$ & $72(20.57 \%)$ \\
\hline 4 & $10(4.25 \%)$ & $1(1.05 \%)$ & $2(11.76 \%)$ & 0 & $13(3.71 \%)$ \\
\hline Total & 457 & 168 & 43 & 08 & 676 \\
\hline $\begin{array}{l}\text { Average no. } \\
\text { of drugs }\end{array}$ & 1.94 & 1.77 & 2.52 & 2.66 & 1.93 \\
\hline
\end{tabular}

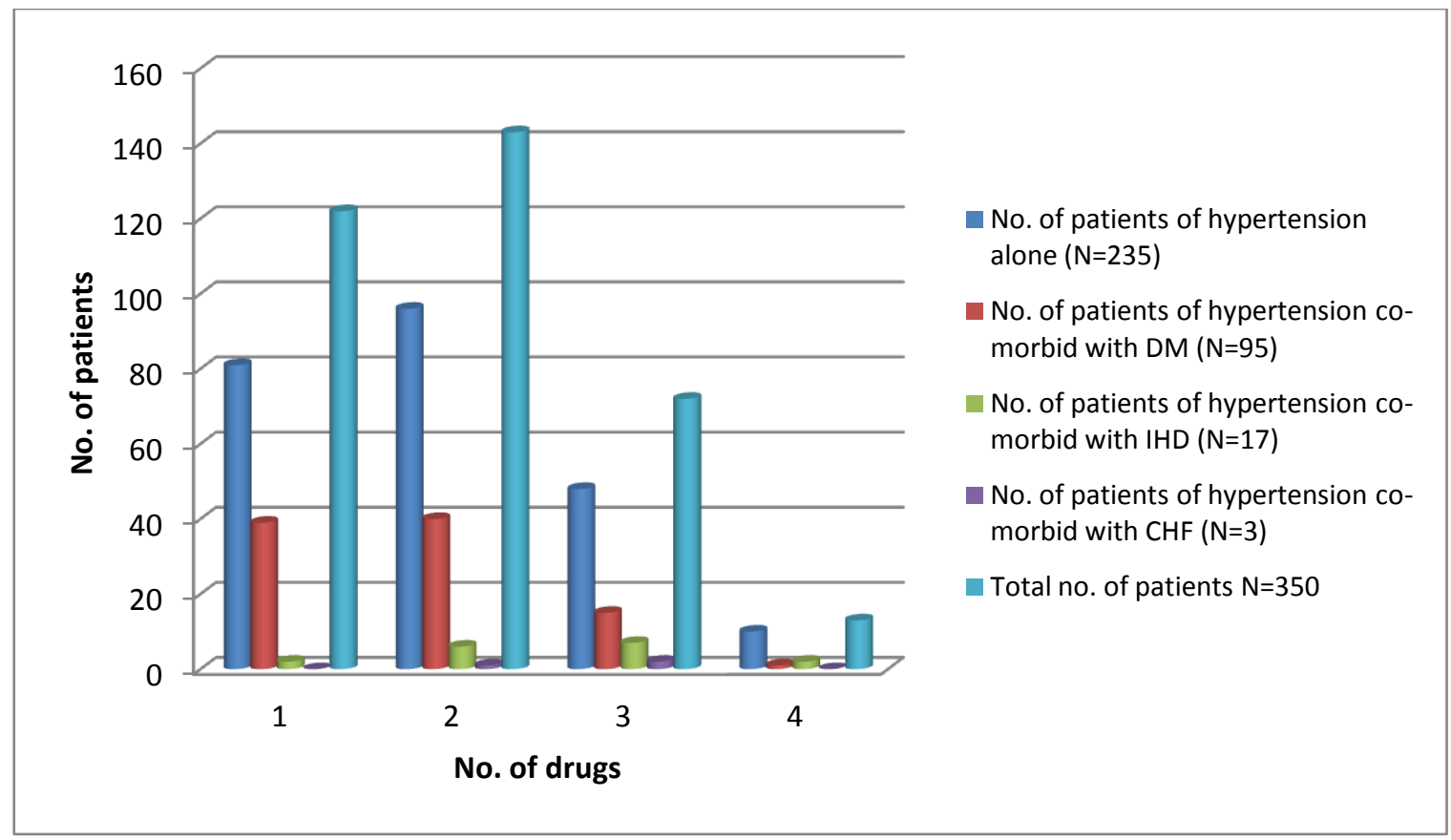

Figure 3: No. of antihypertensive drugs prescribed per prescription. A maximum number of patients $(40.86 \%)$ were on two drugs and only $3.71 \%$ of patients received four drugs. 
Commonly used antihypertensive drugs in study patients

Total of 235 patients was observed without any co-morbidity. Among these patients, Amlodipine was the most common (58.72\%) used the antihypertensive drug followed by
Hydrochlorothiazide in 25.53 patients and Atenolol in $25.11 \%$ patients. Enalapril was prescribed in $17.45 \%$ of patients while Metoprolol was used in $17.02 \%$ patients. Least prescribed was Frusemide and Carvedilol in $1.28 \%$ patients (each), shown in Table 4 and Figure 4.

Table 4: Commonly used antihypertensive drugs (without any comorbidity)

\begin{tabular}{|l|c|c|c|}
\hline Antihypertensive group & Drugs & No. of patients & Percentage(\%) \\
\hline \multirow{2}{*}{ ACE inhibitor } & Enalapril & 41 & 17.45 \\
\hline \multirow{3}{*}{ Angiotensin receptor blocker } & Ramipril & 36 & 15.31 \\
\cline { 2 - 4 } & Losartan & 33 & 14.04 \\
\cline { 2 - 4 } & Telmisartan & 16 & 6.80 \\
\cline { 2 - 4 } & Valsartan & 12 & 5.10 \\
\hline Calcium channel blocker & Amlodipine & 138 & 58.72 \\
\hline \multirow{3}{*}{ Beta-blocker } & Atenolol & 59 & 25.11 \\
\cline { 2 - 4 } & Metoprolol & 40 & 17.02 \\
\cline { 2 - 4 } & Carvedilol & 3 & 1.28 \\
\hline \multirow{3}{*}{ Diuretic } & Hydrochlorothiazide & 60 & 25.53 \\
\cline { 2 - 4 } & Torsemide & 5 & 1.12 \\
\cline { 2 - 4 } & Chlothalidone & 4 & 1.28 \\
\cline { 2 - 4 } & Frusemide & 3 & 2.55 \\
\hline Alpha 2 agonist & Clonidine & 6 & \\
\hline
\end{tabular}

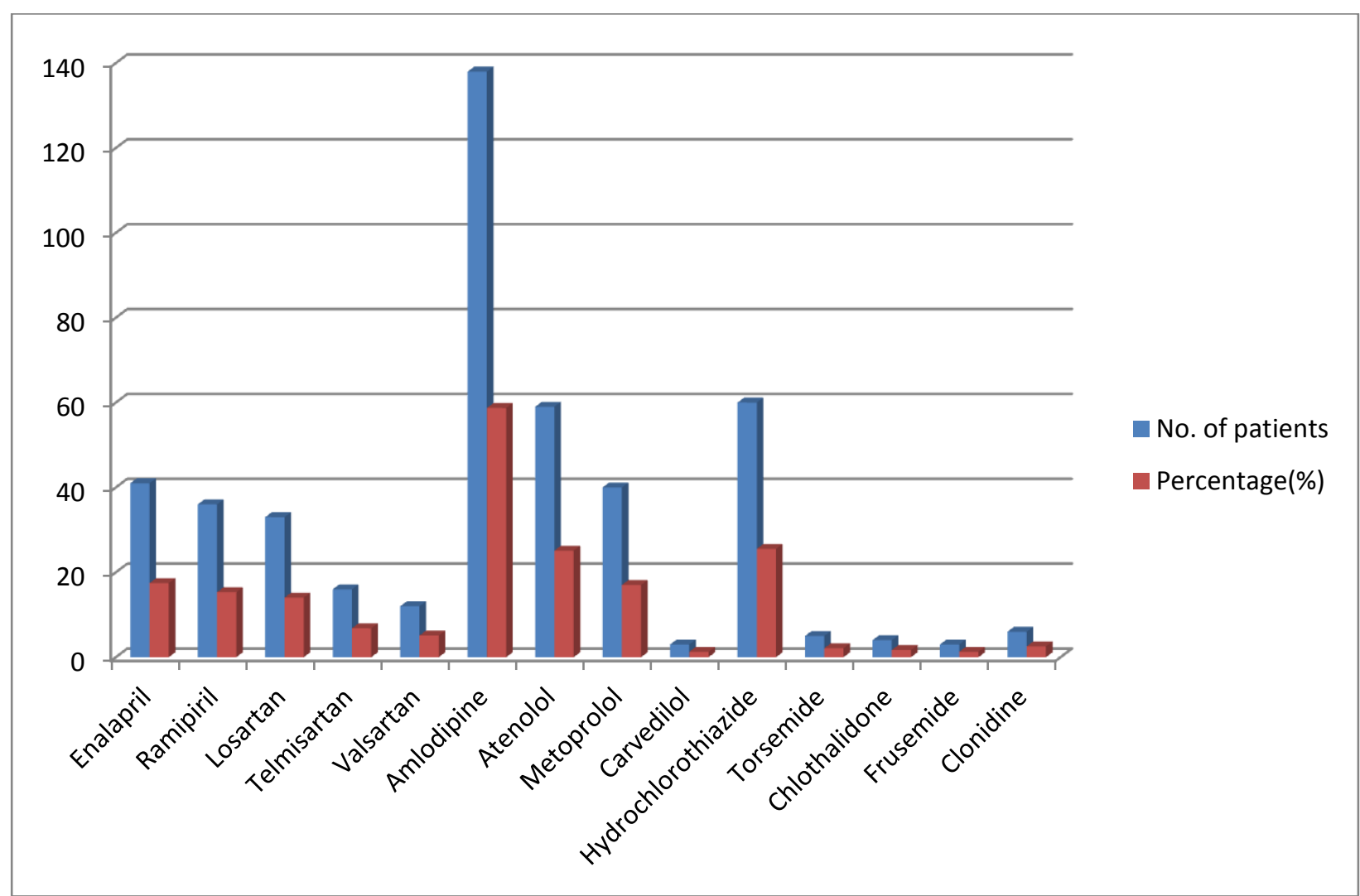

Figure: 4. Commonly used antihypertensive drugs (without any comorbidity). Amlodipine most commonly $(58.72 \%)$ used the antihypertensive drug and second most common antihypertensive drug was hydrochlorothiazide. 
Commonly used antihypertensive group in study patients

Among the antihypertensive groups, calcium channel blockers were the most commonly prescribed antihypertensive group (53.71\%), followed by beta-blockers (44.57\%), ACE inhibitors (41.43\%), diuretics (29.43\%) and ARBs (22.57\%). Alpha agonist (1.71\%) were the least prescribed antihypertensive groups.

Hypertensive patients without any co-morbidities were prescribed with calcium channel blockers most commonly $(58.72 \%)$ while $43.40 \%$ of this patient received group beta blockers. ACE inhibitors and diuretics were the $3^{\text {rd }}$ and $4^{\text {th }}$ most common antihypertensive groups in this category of patients. ACEIs were advised in $32.77 \%$ while diuretics were given $30.64 \%$ of patients. In $2.55 \%$ of these patients, alpha agonist was given.
In a group of patients of hypertension co-morbid with diabetes mellitus, 57(60\%) and 44(46.32\%) patients were prescribed with ACE inhibitors and calcium channel blockers respectively. 37.89\% of patients were prescribed with beta blockers while $18.95 \%$ of patients were given diuretics. $94.12 \%$ patients of hypertension co-morbid with ischemic heart disease(IHD) were prescribed with beta blockers while $58.82 \%$ and $47.66 \%$ were prescribed with diuretics and ACE inhibitors. $35.29 \%$ and $23.53 \%$ of cases were prescribed with calcium channel blockers and angiotensin receptor blockers. All 3 patients of hypertension co-morbid with congestive heart failure (CHF) were prescribed with ACE inhibitors and diuretics. Two of them were prescribed beta blockers.(Table 5, Figure 5)

Table 5: Commonly Used Antihypertensive Group in Study Patients

\begin{tabular}{|l|c|c|c|c|c|}
\hline $\begin{array}{l}\text { Antihypertensive } \\
\text { group }\end{array}$ & $\begin{array}{c}\text { No. of } \\
\text { patients of } \\
\text { hypertension } \\
\text { alone } \\
(\mathrm{N}=235)\end{array}$ & $\begin{array}{c}\text { No. of } \\
\text { patients } \\
\text { hypertensions } \\
\text { co- morbid } \\
\text { DM (N=95) }\end{array}$ & $\begin{array}{c}\text { No. of } \\
\text { patients } \\
\text { hypertension } \\
\text { co-morbid } \\
\text { with IHD } \\
\text { (N=17) }\end{array}$ & $\begin{array}{c}\text { No. of } \\
\text { patients } \\
\text { hypertension } \\
\text { co-morbid } \\
\text { with CHF } \\
\text { (N=3) }\end{array}$ & $\begin{array}{c}\text { No. of } \\
\text { patients (\%) } \\
\text { N=350 }\end{array}$ \\
\hline ACE-inhibitors & $77(32.77 \%)$ & $57(60 \%)$ & $8(47.06 \%)$ & $3(100 \%)$ & $\begin{array}{c}145 \\
(41.43 \%)\end{array}$ \\
\hline Beta blocker & 102 & $36(37.89 \%)$ & $16(94.12 \%)$ & $2(66.67 \%)$ & $\begin{array}{c}156 \\
(44.57 \%)\end{array}$ \\
\hline $\begin{array}{l}\text { Calcium channel } \\
\text { blocker }\end{array}$ & $\begin{array}{c}13.40 \%) \\
(58.72 \%)\end{array}$ & $44(46.32 \%)$ & $6(35.29 \%)$ & $0(0.00 \%)$ & $\begin{array}{c}188 \\
(53.71 \%)\end{array}$ \\
\hline $\begin{array}{l}\text { Angiotensin } \\
\text { receptor blocker }\end{array}$ & $61(25.96 \%)$ & $14(14.74 \%)$ & $4(23.53 \%)$ & $0(0.00 \%)$ & $79(22.57 \%)$ \\
\hline Diuretic & $72(30.64 \%)$ & $18(18.95 \%)$ & $10(58.82 \%)$ & $3(100 \%)$ & $\begin{array}{c}103 \\
(29.43 \%)\end{array}$ \\
\hline Alpha 2 agonist & $6(2.55 \%)$ & $0(0.00 \%)$ & $0(0.00 \%)$ & $0(0.00 \%)$ & $6(1.71 \%)$ \\
\hline
\end{tabular}




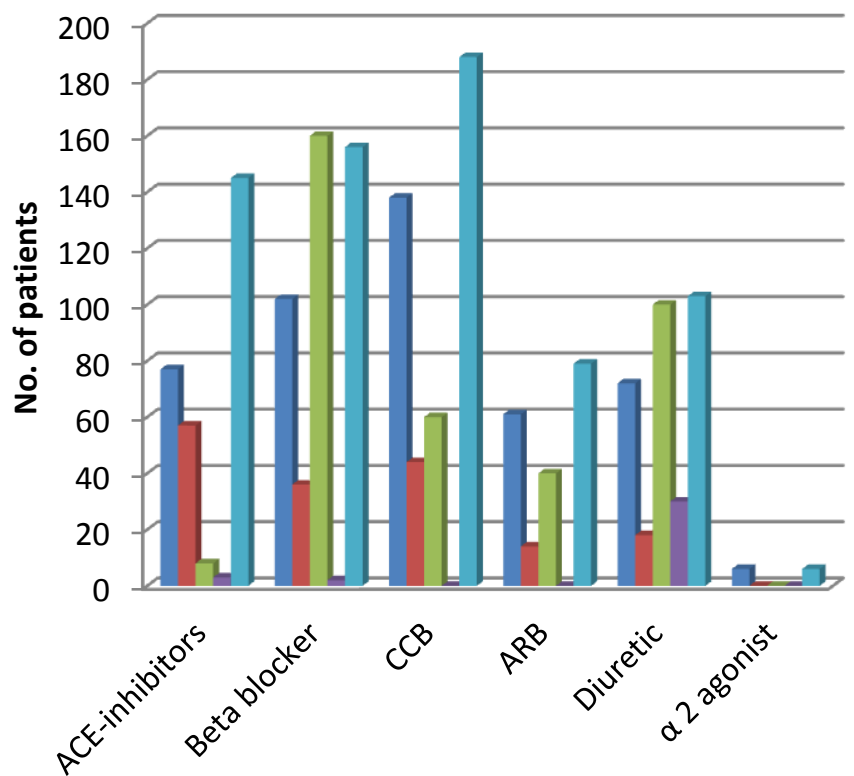

No. of patients of hypertension alone $(\mathrm{N}=235)$

No. of patients hypertensions co- mobid DM ( $\mathrm{N}=95)$

No. of patients hypertension co-morbid with IHD ( $\mathrm{N}=17)$

No. of patients hypertension co-morbid with $\mathrm{CHF}(\mathrm{N}=3)$

No. of patients (\%) N=350

Antihypertensive group

Figure: 5 Commonly used antihypertensive group in study patients., Calcium channel blockers were the most commonly prescribed antihypertensive group (53.71\%) and Alpha agonist $(1.71 \%)$ was the least prescribed antihypertensive group.

Fixed Dose Drug Combination (Fdc) received two FDCs and these six patients were of Antihypertensive Prescribed hypertension alone. So a total of 144 FDCs was Out of 350 patients, $138(39.42 \%)$ were prescribed prescribed. (Table6, Figure 6.)

fixed-dose drug combination. Six patients

Table 6 Fixed dose drug combination antihypertensive prescribed

\begin{tabular}{|l|c|c|c|c|c|}
\hline & $\begin{array}{c}\text { Hypertension } \\
\text { Alone }\end{array}$ & $\begin{array}{c}\text { Hypertension Co- } \\
\text { morbid with } \\
\text { Diabetes Mellitus }\end{array}$ & $\begin{array}{c}\text { HTN+ } \\
\text { IHD }\end{array}$ & $\begin{array}{c}\text { HTN+ } \\
\text { CHF }\end{array}$ & $\begin{array}{c}\text { Total } \\
\text { FDCs }\end{array}$ \\
\hline $\begin{array}{l}\text { No of } \\
\text { FDCs }\end{array}$ & 116 & 22 & 6 & 0 & 144 \\
\hline
\end{tabular}

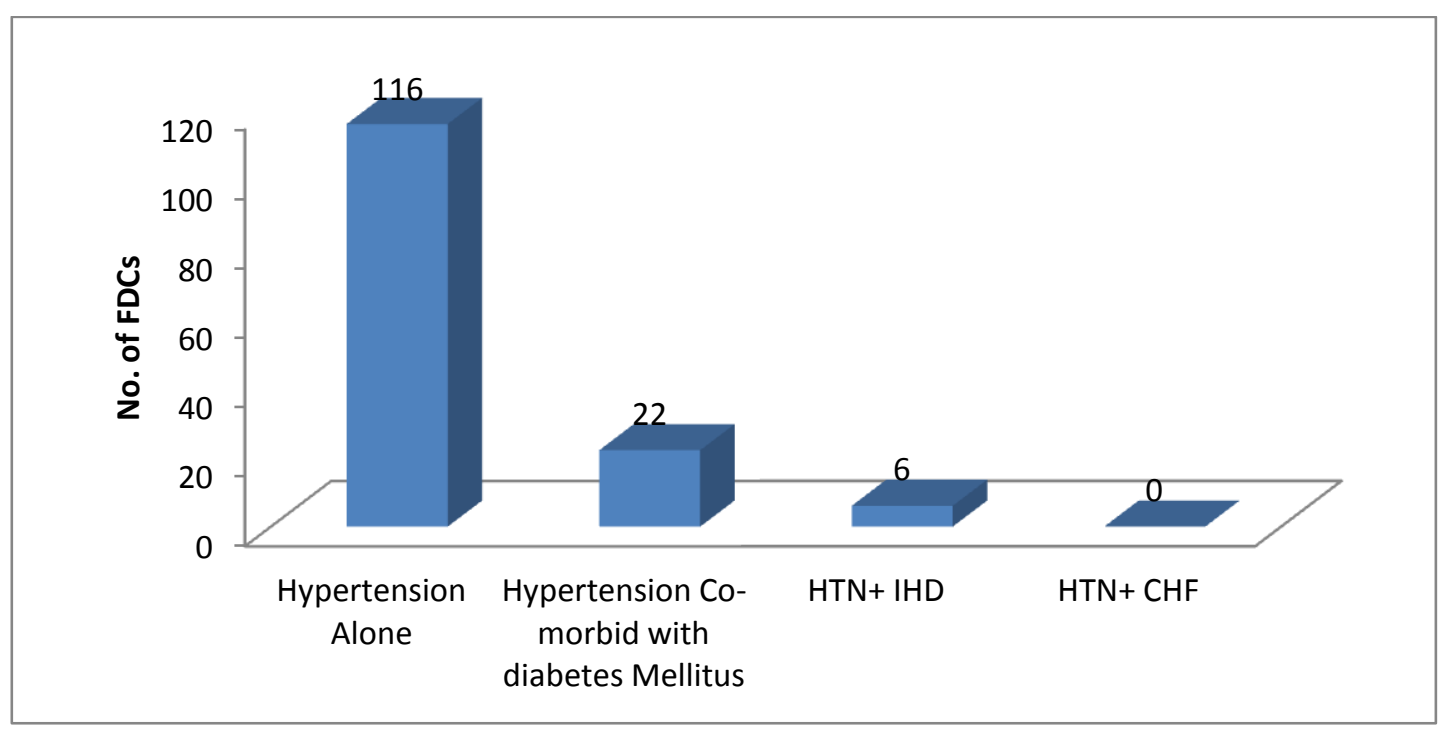

Figure: 6 Fixed Dose Drug Combination (FDC) Antihypertensive Prescribed. Maximum number of FDCs were prescribed for hypertension alone followed by hypertension with diabetes. 


\section{Types of Fixed Dose Combinations}

Total nine types of FDCs have been prescribed to the patients. Four of them were containing hydrochlorothiazide as one component while another drug was losartan, telmisartan, valsartan, and enalapril respectively. Rest of the FDCs contained beta blocker as one component - two contained metoprolol and one had atenolol. Atenolol + amlodipine FDC was the most commonly used FDC (40.28\%) followed by amlodipine + metoprolol $(22.22 \%)$ and losartan + hydrochlorothiazide (13.19\%). Telmisartan+ amlodipinewas the least prescribed FDC (.69\%) shown in table7 and figure 7.

Table 7 Type of Fixed-dose drug combination antihypertensive prescribed

\begin{tabular}{|l|c|c|}
\hline Types of FDC & No. of FDCs & Percentage \\
\hline Atenolol+amlodipine & 58 & 40.28 \\
\hline Enalapril+hydrochlorthiazide & 10 & 6.94 \\
\hline Losartan+hydrochlorthiazide & 19 & 13.19 \\
\hline Metoprolol+amlodipine & 32 & 22.22 \\
\hline metoprolol+ramipril & 6 & 4.17 \\
\hline Telmisartan+hydrochlorthiazide & 13 & 9.03 \\
\hline Telmisartan+amlodipine & 1 & 0.69 \\
\hline Telmisartan+chlorthalidone & 3 & 2.08 \\
\hline Valsartan+hydrochlorthiazide & 2 & 1.39 \\
\hline Total & 144 & 100 \\
\hline
\end{tabular}

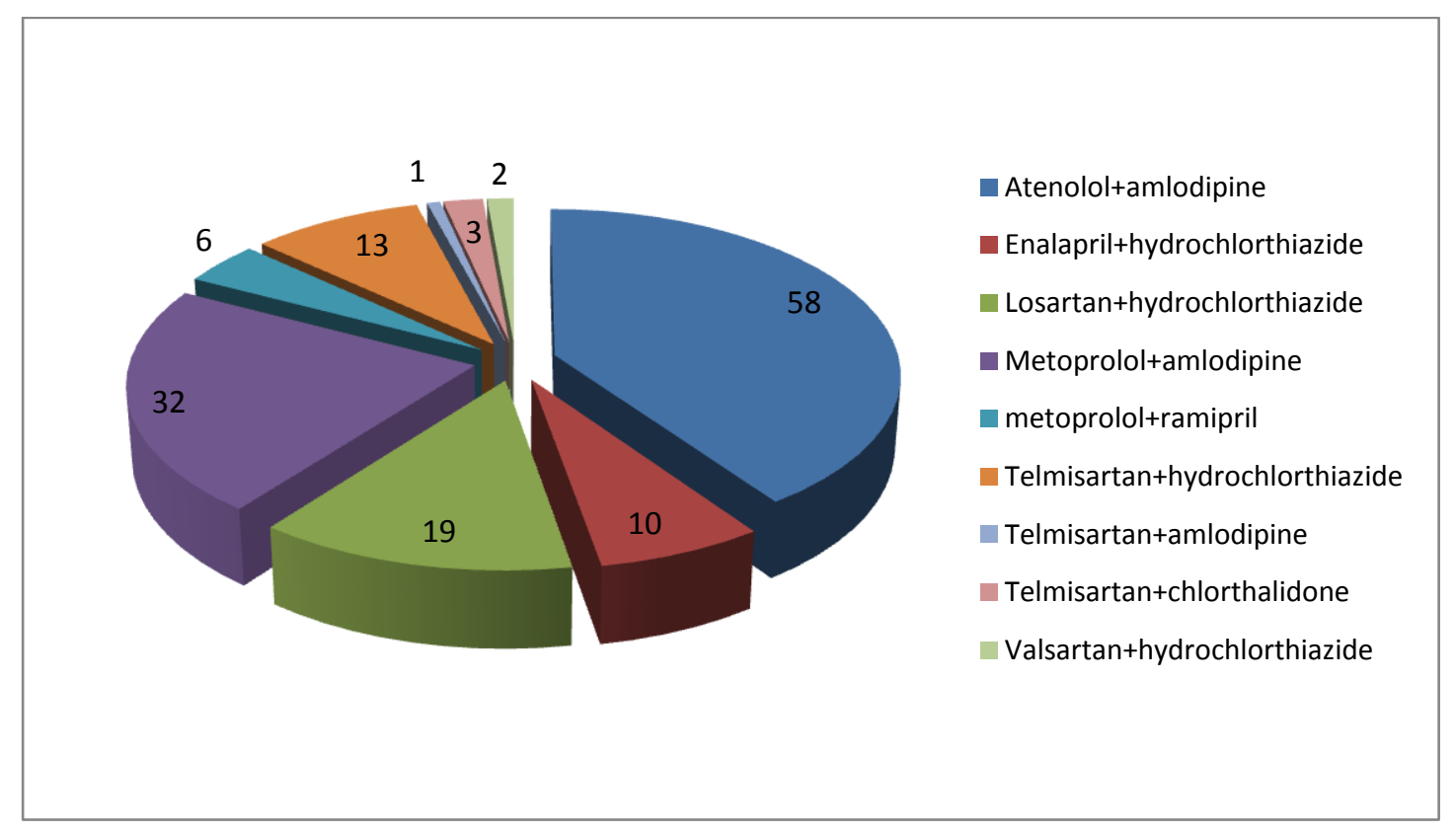

Figure 7: Type of Fixed-dose drug combination antihypertensive prescribed. Most common FDC drug prescribed was Atenolol+Amlodipine followed by Metoprolol+Amlodipine.

\section{Discussion}

Hypertension is a chronic disease requiring lifelong treatment. Although lifestyle modifications play an important role in hypertension management, drugs become unavoidable in many patients.
In our study, $34.85 \%$ of patients were stabilized on monotherapy. A study conducted by Pai et al ${ }^{11}$ reported monotherapy in $49 \%$ of hypertensive patients. While Etuk et al ${ }^{12}$ found monotherapy was used only in $20 \%$ cases of hypertension. 
Majority of our patients $(65.15 \%)$ were on multiple drug therapy. There is a favorable disposition to combination therapy in recent years particularly in patients with more difficult to control BP (often encountered in tertiary or referral settings). ${ }^{13}$ There is a rational justification for such therapy because the multifactorial nature of hypertension is addressed, BP control and achievement of target BP tends to be better, and the risk of side effects owing to use of maximal doses of mono therapeutic agents is reduced.

In our study, the average number of antihypertensive drugs in hypertension alone was (1.94) and an average number of antihypertensive drugs in comorbid IHD cases was (2.52). In hypertension co-morbid with DM, an average number of antihypertensive (1.77). This may be explained by $4.25 \%$ and $11.76 \%$ cases of hypertension alone and with IHD have been prescribed four antihypertensive drugs while a maximum number of antihypertensive prescribed to comorbid DM cases was two. An average number of antihypertensive is high in co-morbid CHF and IHD cases which were more than 2.5 in each condition. It seems reasonable because hypertension comorbid with these conditions is difficult to treat and require multiple drug therapy. All cases of these patients received two or more than two antihypertensive drugs.

In this study, ACE inhibitors were found the most commonly (60\%) prescribed antihypertensive group in patients of diabetic hypertensive. This finding is in consonance with the a study by Sandozi and Emani ${ }^{14}$ who reported $50 \%$ of diabetic hypertensive patients were on ACEinhibitors. In this study, all cases of hypertension with CHF ACE inhibitors were prescribed. Jackson $^{15}$ also found ACE inhibitors were prescribed in $74.70 \%$ of cases of hypertension with CHF cases. Several large, randomized trials of participants with nondiabetic kidney disease determined that regimens including ACE inhibitors are more effective in reducing the occurrence of kidney endpoints compared to regimens not including ACE inhibitors. ${ }^{16}$
Beta-blocker was the most commonly prescribed antihypertensive drug group (94.12\%) in hypertensive IHD cases. Beta-blockers improve survival in patients of CHF cases and this is due to antagonism of ventricular wall enhancing, apoptosis promoting and pathological remodeling effects of the excess sympathetic activity. ${ }^{17}$

In this study, CCBs was the most commonly prescribed antihypertensive group $(58.72 \%)$. Same results were found in QUADS study ${ }^{18}$ in which they reported CCB (65\%) were the most commonly prescribed drugs. Pai et al ${ }^{11}$ also found reported calcium channel blockers (49\%) as the most commonly prescribed drugs. In our study, CCBs were found the most commonly prescribed group in diabetic hypertensive patients. Teemu Ahola found that beta blocker and ACE inhibitors were the leading class of drug in hypertension comorbid with diabetes. ${ }^{19}$

In this study, thiazide diuretics were prescribed $18.28 \%$ of patients. Thiazide-type diuretics have been the basis of antihypertensive therapy in most

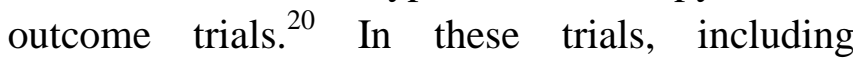
Antihypertensive and Lipid-Lowering Treatment to Prevent Heart Attack Trial (ALLHAT) ${ }^{21}$, diuretics have been virtually unsurpassed in preventing the cardiovascular complications of hypertension. The present study found, $39.42 \%$ of patients received fixed-dose combinations. FDCs containing beta blocker and CCB were found most commonly used. Amlodipine + atenolol was most commonly prescribed drug combination in 40.28\% patients. These FDCs though are recommended by JNC- VIII guidelines ${ }^{22}$. Pai et $\mathrm{al}^{11}$ found ARB with a diuretic $(25.4 \%)$ was the most frequently prescribed two-drug combination which was not according to our study.

\section{Conclusion}

Hypertension and its complications can be control by diet, regular exercise, medicines and by time to time follow up. Most commonly prescribed drugs were $\mathrm{CCB}$ was most commonly prescribed drugs in this study and ACE inhibitors were most commonly prescribed in diabetic patients. While 
most common prescribed antihypertensive drug in IHD patients was Beta blockers.

\section{Limitations of the Study}

The study populations size was small so it was not representative of the entire population, and the duration of the study was short.

\section{Acknowledgments}

The authors express their thanks to Dr. Manoj Kumar Lakhotiya (HOD), Department of Medicine, Dr. S.N. Medical College, Jodhpur for his assistance in conducting the study.

\section{Conflict of Interest}

The authors declare that no conflict of interest, financial or otherwise exists.

\section{References}

1. Go, AS, Mozaffarian D, Roger VL, American Heart Association Statistics Committee and stroke statistics subcommittee, et. al. Heart Disease and stroke statistics-2014 update: A report from the American Heart Association. Circulation. 2013; 129: e 28-292.

2. Third Indian Guidelines on Hypertension ( IGH)- III [ Cited 2013, October 14] Available from : http://www. japi.org/ february _2013_special_ issue_hypertension__ guideline/06_ epidemiology_of_hypertension.html

3. Gaziano T, Reddy KS, Paccaud F, Horton S, Chaturvedi V. Cardiovascular disease. In: Jamison DT, Mosley WH, editors. Disease Control Priorities in the Developing World. Oxford: Oxford University Press; 2006. p. 645-62.

4. National programme for prevention and control of cancer, diabetes, cardiovascular diseases and stroke ( NPCDCS) Operational Guidelines. Directorate General of Health Services, Ministry of Health and Family Welfare, Government of India.
5. 2003 European Society of Hypertension/ European Society of Cardiology Guidelines for the management of arterial hypertension. Journal of Hypertension, 2003, 21; 1011-1053.

6. PM Esunge. From blood pressure to hypertension: the history of research. $\mathrm{J}$ of the Royal Soc of Med. 1991; 84:621.

7. Rimoy GH, Justin Temu M, Nilay C. Prescribing patterns and cost of Autihypertensive drugs in private hospitals in Dar es Salaam, Tanzanai. East Cent Afr J Pharm Sci. 2008; 11:69-73.

8. Kotchen TA. The Search for strategies to control hypertension circulation. 2010; 122:1141-3.

9. Dukes MNG. Development from Crooks to the nineties. In: Auditing drug therapy: approaches towards rationality at reasonable costs: proceedings from an international symposium. Stockholm: Swedish Pharmaceutical Press; 1992.

10. World Health Organization. Introduction to drug utilization research. Geneva: World Health Organization; 2003.

11. Pai PG, Shenoy J, Sanji N. Prescribing patterns of antihypertensive drugs in a South Indian tertiary care hospital. Drug Invention Today: 2011; 3(4), 38-40.

12. Etuk E, Isezuo SA, Chika A, AkucheJ, Ali M. Prescription pattern of antihypertensive drugs in a tertiary health institution in Nigeria. Annals of African Medicine. 2008; 7(3):128 - 132.

13. Adigun AQ, Ishola DA, Akintomide AO, Ajayi AAL.Shifting trends in the pharmacologic treatment of hypertension in a Nigerian tertiary hospital: a realworld evaluation of the efficacy, rationality and pharmaco-economics of old and newer antihypertensive drugs. J Hum Hypertens 2003; 17: 277-285.

14. Sandozi T, Emani VK. Survey of prescription pattern of anti-hypertensive drugs in hypertensives \& hypertension 
associated diabetics. International $\mathbf{J}$ Pharma and Bio Sciences: 2010; 1(4):2326.

15. Jackson H. James, Sobolski John, Krienke Russ, Wong Ken S., Feride Frech-Tamas, Nightengale Brian, Blood pressure Control and pharmacotherapy patterns in the United States before and after the release of the Joint National Committee on the Prevention, Detection, Evaluation, and Treatment of High Blood Pressure (JNC 7) Guidelines. J Am Board Fam Med 2008;21:512-21.

16. Schoolwerth AC, Sica DA, Ballermann BJ, Wilcox CS: Renal considerations in angiotensin converting enzyme inhibitor therapy: A statement for healthcare professionals from the Council on the Kidney in Cardiovascular Disease and the Council for High Blood Pressure Research of the American Heart Association. Circulation 104:1985-1991, 2001)

17. Tripathi KD. Antihypertensive drugs. Essentials of medical pharmacology. 7th ed.. New Delhi: Jaypee; 2013. p. 558-574.

18. Bernard MY, Wong YL, Lau CP. Queen Mary Utilization of Antihypertensive Drugs Study(QUADS): use of antihypertensive drug classes in the Hypertension Clinic 1996-2004. Br J Clin Pharmacol. 2005; 60(1):90-97.

19. Ahola T. Antihypertensive drug therapy in Finland: Utilization of Antihypertensive Medication, Control of Blood Pressure, and Achievable Reduction of Cardiovascular Morbidity with Intensified Treatment.[ academic dissertation]. Turku: National Institute for Health and Welfare; 2013[ cited 2013, October 15]. Available from : http://www.julkari.fi/ bitstream/ handle 10024/104453/URN_ISBN_978952-245-862-9.pdf? sequence $=1$
20. Psaty BM, Smith NL, Siscovick DS, et al. Health outcomes associated with antihypertensive therapies used as first-line agents. A systematic review and metaanalysis. JAMA.1997;277:739-45.

21. ALLHAT Officers and Coordinators for the ALLHAT Collaborative Research Group. Major outcomes in high-risk hypertensive patients randomized to angiotensin-converting enzyme inhibitor or calcium channel blocker vs diuretic: The Antihypertensive and Lipid-Lowering Treatment to Prevent Heart Attack Trial (ALLHAT). JAMA， 2002; 288:29812997.

22. Chobanian AV, Bakris GL, Black HR, Cushman WC, Green LA, Izzo JL et al. The eighth report of the Joint National Committee on Prevention, Detection, Evaluation, and Treatment of High Blood Pressure. The JNC VIII report. JAMA 2014; 311(5):507-250. 